\title{
Strangulated PHREnic hernia in a HORSE.
}

BY CHARLES M. WOOD, VETERINARY SURGEON.

\section{To the Editor of the Boston Medical and Surgical Jcurnal.}

Sir,--I feel some diffidence in approaching the pages of your Journal, but hope that the following case in veterinary medicine may possess sufficient interest to render it acceptable to some of your many readers.

Wednesday, March 10th, 2, P.M., I was requested to visit (at Ward's stable) a horse, the property of a physician of this city. On my arrival, I found my subject (a bay horse, 13 years old and in good working condition), to be laboring under the following symptoms. Profuse perspiration; extreme restlessness, and hurried respiration ; pawing violently; suddenly throwing himself down and rolling on his back; lying in that position only for a few seconds, then quickly rising again, to resume his pawing and scraping as before. These symptoms were accompanied by severe spasmodic contractions of the abdominal muscles. On inquiry of the owner, who was present, he informed me that he had driven the horse during that forenoon; but although he was not in his usual spirits, he saw no trouble with him till 12 , M., when he was discovered pawing and attempting to lie down in the street where he had been left standing. He was immediately taken to the stable, and an attempt made to give him medicine, which the violence of the symptoms rendered extremely difficult to do. However, assisted by those present, I raised the animal's head for the purpose of giving him an antispasmodic drench, which was composed of tincture of opium, $z \mathrm{j}$.; sulphuric ether, $z$ ij.; water, $z$ viij. This he stoutly resisted, and in his struggles he was thrown down. Being secured in this position, the medicine was easily administered. I also gave an injection of laudanum, \&c., per rectum, and he was then allowed to get up ; but he was no sooner on his feet than he walked into the stall and commenced pawing as before. I then applied a stimulating liniment to the abdomen, which at first excited him very much, but after a while appeared to give some relief. This, however, was of short duration. I visited him again at 4, P.M. Found him standing, pawing, and frequently looking back to the left side, which was evidently the seat of disease. I walked quietly into his stall, and carefully examined him. The pulse was 64, and feeble; the respiration painful and laborious; the whole body, especially the extremities, very cold ; the pupils dilated, and the eyes wild and staring. I repeated the medicine, and also the injection. At 6, P.M., there was no abatement of the symptoms; he was still standing, not having laid down during my absence; he was constantly pawing, first with one foot and then with the other, the body and extremities remaining cold, and the pulse depressed and small. I now gave up all hope of his recovery, being of the opinion that some serious lesion of the stomach, diaphragm or intestines must have taken place. He appeared now to suffer little pain, being, as I supposed, under the influence of the opiates; but his tail was trembling, the head thrown up and down, it being often turned to the left side as before. I offered him some tepid 
water, of which he drank moderately; gave him an injection of soap and water, had him well covered, and left him. At 10, P.M., he was still standing, and pawing as usual; respiration quick and more laborious, with a general tremor of the whole body; great anxiety, and rapidly increasing prostration. He was evidently sinking.

Thursday, 11 th, $7 \frac{1}{2}$, A.M., visited my patient, just in time to see him fall dead in his stall. This was about nineteen hours after the attack.

Post-mortem Examination, eight hours after death.-Present, Professor J. B. S. J., Dr. C. and Dr. G. On removing a portion of the large intestines, the stomach appeared, very much distended, but was otherwise healthy. There was discovered inmediately a rupture in the tendinous portion of the diaphragm, of about three inches in length, and on the left side, through which some ten or twelve yards of the small intestines had been forced into the chest, completely strangulated and in the highest state of congestion. There was, also, a rupture, nine or ten inches in length, of the muscular portion of the diaphragm on the same side. That these ruptures were the immediate cause of death, there is of course no doubt. It is also probable that the lesion must have occurred recently, for such an injury usually proves very speedily fatal. The rupture may, however, have happened some days previously to the strangulation.

The causes of rupture of the diaphragm are very obscure; but $I$ think it is usually the consequence of sudden and violent exertion; although it might in this case have been superinduced by the over-distended state of the stomach.

Boston, April 6, 1852.

\section{DEATH WHILE UNDER THE INFLUENCE OF THE TINCTURE OF CHLOROFORM.}

[Communicated for the Boston Medica] and surgical Jourual.]

EmiLe, a sailor, 20 years of age, a Swiss, a tall and remarkably finelooking man, entered this Hospital on the loth of March, 1852. Report by those who brought him here, and subsequently made by himself during his convalescent state, was, that somewhere about the 20th of February, the great toe on his right foot was frost-bitten. About a week after this, was taken with fever, and his "bed-place" aboard ship, which was bound to this port from Liverpool, was almost constantly wet, and he had not much care bestowed upon him. On arrival, the men made him drink.

He had ship-fever. At the time of entrance, he was under some considerable mental excitement-talking foolishly-had looseness of the bowels and eruption on the abdomen. As mental excitement subsided, he began to complain of pain in toe, the last phalanx of which was black and hard.

The fever yielded rather kindly ; but pain in the toe was great, very much more so than in a majority of the many cases of the kind, of 